\title{
A DISFUNÇÃO SEXUAL ENQUANTO DIAGNÓSTICO DE ENFERMAGEM - CARACTERÍSTICAS DEFINIDORAS ENCONTRADAS EM LESADOS MEDULARES
}

Ana Cristina Mancussi e Faro*

FARO. A.C.M. e A disfunçăn sexual enquanto diagnóstico de enfermagem - características definidoras encontradas em lesados medulares. Rev. Wsc. Finf.USP. v 29. n.2.p.166.72 ago 1995 .

A disfunção sexual decorrente da lesão medular é uma das áreas que mais necessita de assistência em função dos aspectos culturais, psicológico e biológico que a sustenta. Assim, propusemo-nos a identificar as caracteristicas definidoras que fundamentaram o diagnóstico de enfermagem disfunção sexual. segundo a Taxonomia I da NANDA. em descrições feitas pelos enfermciros nos históricos de enfermagem de lesados medulares vinculados a programa de reabilitação entre 1988 e $1992 \mathrm{e}$. constatamos que este diagnóstico foi fundamentado pela disfunção erétil e ejaculatória, bem como pela inatividade sexual decorrente das alterações físicas.

I NITERMOS: Disfunção sexual. Lesão medular. Reabilitação.

\section{INTRODUÇÃO}

listamos vivenciando alteraçoes nos costumes sociais. onde se evidencia cada ve\% mais o culto a beleya fisica e a sensualidade o de alguma maneira. isto seria um privilegio daqueles tidos como normais ou saudaveis. No entanto. o contingente de pessoas portadoras de lesão medular. soliretudo de etiologia traumatica. vem aumentando em uma progressão alarmante.

Ainda que nāo tenham superado as harreiras de defesa da própria intimidade, os lesados medulares se sentem cada ver mais inclinades a louscar

\footnotetext{
* Enfermeira. Docente do Departamento de Enfermagem Médico-Cirúrgica da Escola de Enfermagem da USP
} 
informações por meios variados, recorrendo, em muitas ocasiões a qualquer profissional da equipe de saúde, que lhe inspire confiança, para perguntar sobre os problemas que estão ocorrendo na sua vida sexual.

SPICA (1989) ao tecer alguns comentários sobre o preparo de enfermeiras para o aconselhamento sexual, esclarece que a sexualidade humana é uma área de estudo relativamente nova para os profissionais de saúde.

Atuando junto ao lesado medular em programa de reabilitação, os enfermeiros têm demonstrado preocupação com os cuidados referentes à mobilidade e locomoção, reeducação vésico-intestinal e com a integridade da pele, colocando em segundo plano a assistência voltada para a orientação da função sexual do paraplégico.

Diante disso, surgiu o interesse em pesquisarmos se as enfermeiras tem abordado essa problemática durante a coleta de dados para o planejamento da assistência de enfermagem desses pacientes.

Assim, propomos como objetivos desse estudo:

- identificar as alterações da atividade sexual dos lesados medulares em programa de reabilitação descritas pelas enfermeiras nos históricos de enfermagem.

- verificar se essas alterações fazem parte das características definidoras do diagnóstico de disfunção sexual proposto pela NANDA.

\section{MATERIAL E MÉTODO}

Este estudo faz parte de uma pesquisa mais abrangente, a qual vem sendo realizada junto à Divisão de Medicina de Reabilitação do Hospital das Clínicas da Faculdade de Medicina da USP.

Os dados foram coletados dos Históricos de Enfermagem anexados aos prontuários de pacientes portadores de lesão traumática da medula espinhal e que estavam em programa de reabilitação durante o período de 1988 e 1992 .

A própria autora da pesquisa realizou a coleta de dados mediante os registros feitos nos Históricos de Enfermagem preenchidos pelas enfermeiras da equipe de lesão medular, durante a consulta de enfermagem.

Para a identificação das características definidoras dos diagnósticos, foi utilizada a Taxonomia I revisada da North American Nursing Diagnosis Association (NANDA) de 1989. 


\section{RESULTADOS E COMENTÁRIOS}

O estudo dos 38 Históricos de Enfermagem anexados aos prontuários de pacientes em programa de reabilitação, permitiu-nos identificar as características definidoras que fundamentaram a elaboração do diagnóstico disfunção sexual.

Inicialmente, serão comentados os dados referentes à caracterização dos pacientes, o que acreditamos ser importante para as análises posteriores.

Considerando o levantamento de 38 prontuários que tinham Histórico de Enfermagem preenchidos, constatamos que 33 deles pertenciam a pacientes do sexo masculino $(86,81 \%)$ e apenas $5(13,16 \%)$ eram de pacientes do sexo feminino.

Com relação a idade, na faixa etária de 18 a 22 anos encontramos 6 $(15,80 \%)$ pacientes, outros $19(50,0 \%)$ com idade entre 23 e 32 anos e para a faixa etária entre 33 e 50 anos, verificamos 11 (28.94\%) pacientes. Havia 1 (2,63\%) paciente com 14 anos e outro com 17 anos de idade $(2,63 \%)$.

Autores como BO(AOSSIAN (1981), SPOSITO et al (1986). FARO) et al (1987) e (1991), SAN'TOS (1989), CRI(גLER (1994), apontam o predomínio de uma população jovem de lesados medulares, com idade entre 18 e 35 anos, $e$ do sexo masculino, proporção aproximada de quatro homens para uma mulher.

Quanto à escolaridade, os registros somaram 21 pacientes $(55,26 \%) \mathrm{com}$ escolaridade em nível de $1^{\circ}$ grau, $11(28,94 \%)$ em nível de $2^{\circ}$ grau. $4(10.52 \%)$ pacientes com nível universitário. Apenas dois Históricos de Enfermagem não tinham este item preenchido.

No que se refere ao nível de lesão pudemos constatar que $20(52.63 \%)$ pacientes haviam sofrido trauma em nível de coluna torácica, $6(15.78 \%) \mathrm{em}$ nível de coluna cervical, outros 6 pacientes em nivel de coluna lombar. I $(2,63 \%)$ com lesão medular em nivel de $T_{12}-L_{1}$ e 5 pacientes $(13.15 \%)$ em nível de $\mathrm{C}_{7} \cdot \mathrm{T}_{1}$.

MENI)()NCCA NETT() et al (1985), SP()SITO) et al (1986) e FARO) (1991) analisaram o nivel de lesão medular e afirmam existir uma predominância de ocorrência de lesão em coluna torácica, em função de que este segmento da coluna o bastante móvel o extenso.

Os resultados encontrados em relação as características dos pacientes reafirmam a necessidade de orientação dessa população alertando para os fatores de risco com o uso de arma de fogo, mergulho em aguas rasas e quedas, principalmente associadas a atividades laborativas, por serem estas al. gumas das causas que determinam a lesão medular na população jovem e produtiva. 
O diagnóstico disfunção sexual foi formulado para 5 pacientes $(13,15 \%)$ à partir das descrições feitas pelas enfermeiras nos Históricos de Enfermagem, definido pela NANIA como o estado em que o indivíduo experimenta uma mudança na função que é vista como insatisfatória, não compensadora $e$ inadequada.

Vale esclarecer que no Histórico de Enfermagem, não há um item ou uma pergunta claramente relacionada à função sexual. Segundo as enfermeiras da equipe de lesado medular, quando abordam este assunto, fazem. no junto aos itens que se referem à eliminações (urinaria, fecal e menstrual). Então, podemos afirmar somente 5 pacientes, do sexo masculino, foram indagados sobre esta questão.

FARO (1991) com o objetivo de identificar o procedimento dos pacientes paraplégicos frente as alterações da função sexual, obteve, com maior freqüência, a resposta de que "não tem qualquer procedimento" face às alterações da função sexual. No entanto, dos pacientes que citaram algum procedimento, foi possivel verificar a diversidade desses procedimentos, onde podemos crer na falta de orientação.

Tais resultados pressupõem que o diagnóstico disfunção sexual poderia estar sendo formulado para um contingente maior de pacientes, no entanto. o número de pacientes com tal diagnóstico ó restrito, talvez, em virtude de ambos, tanto o enfermeiro quanto o lesado medular não estarem a vontade para abordar o assunto. Para que isso ocorra acreditamos que seja necessário, por parte do enfermeiro que este tenha algum conhecimento do assunto e, conseqüentemente. transmitindo segurança ao paciente. Já, por parte do paciente te necessário que ele sinta disposição em expressar suas dúvidas. Muitas vezes, o que está acontecendo o que o paciente apresenta outros problemas, como úlceras de pressão, infeccão urinária os quais superam a disfunção sexual, de acordo com as prioridades individuais.

FAR(), 1991 obteve resultados interessantes quando indagou aos pacientes sobre de quem eles gostariam de receber orientações quanto à disfunção sexual e verificou que a maioria dos pacientes expressou interesse em receber orientações sem estarem preocupados com o profissional. Apenas, esclareceram de que gostariam que o profissional conhecesse o assunto.

()utros aspectos a considerar são o quando e como receber as orientações, sendo verbalizado pela maioria dos pacientes que gostariam de estar trabalhando estas informações durante a internação e na fase de preparo para alta hospitalar, individualmente (FARO, 1991).

Diante do exposto, podemos afirmar que há uma necessidade clara, por parte dos lesados medulares, de estarem esclarecendo suas dúvidas. bem como. da parte do enfermeiro em se preparar melhor. por meio de estudos e pesquisas. para assistir a esta clientela. 
Assim, podemos, retomar a definição proposta pela NANDAA (FARIAS. 1990 ) onde a disfunção sexual o o estado em que o indivíduo experimenta uma mudança na função sexual que 6 vista como insatisfatória, não compensadora e inadequada sendo fundamentada pelas características definidoras como verbalização do problema, alteração na realização do papel sexual percebido, limitação real ou percebida, imposta por doença ou terapia, conflito de valores, alteração no modo de atingir satisfação sexual, inabilidade para alcançar a satisfação desejada. busca de confirmação de ser se. xualmente desejavel, alteração em relacionamento com pessoa significativa. mudança de interesse por si e pelos outros.

É oportuno retomarmos uma definição de termos e. quanto a isto. pudemos verificar que os termos sexualidade e função sexual eram usados pela maioria dos autores e profissionais da área de saúde, sem qualquer distin. ção. Optamos então pelo termo alteração da função sexual ou disfunção se. xual por entendermos que a função sexual esteja relacionada a uma função física. o que significaria um dos aspectos da sexualidade.

$\Lambda$ formulação deste diagnóstico está pautada pela inatividade sexual decorrente das alterações físicas, bem como da disfunção erétil e ejaculatória. e que estavam registrados nos históricos de enfermagem: apresentados na tabela 1.

Tabela 1 - Características que fundamentaram o diagnóstico Disfunção sexual. São Paulo. 1993.

\begin{tabular}{|l|c|l|c|}
\hline DIAGNÓSTICO & $\mathbf{N}$ & \multicolumn{1}{|c|}{ CARACTERÍSTICAS } & N \\
\hline $\begin{array}{l}\text { Disfunção } \\
\text { sexual }\end{array}$ & 5 & $\begin{array}{l}\text { Refere estar sem atividades sexual em } \\
\text { decorrência das alterações físicas } \\
\text { Refere estar com a ereção pouco resistente e } \\
\text { com a ejaculação ausente }\end{array}$ & 2 \\
\hline
\end{tabular}

Anteriormente a esta pesquisa foi estudado uma população de $40 \mathrm{ho-}$ mens paraplégicos no tocante à disfunção sexual e, por meio de depoimentos destes pacientes, 33 deles nos forneceram dados que nos levam a crer que apresentaram ereção psicogênica e a ejaculacão estava ausente na maioria deles. (FARO, 1991).

A disfunção sexual decorrente da lesão medular está diretamente relacionada ao nivel e grau da lesão, hem como o tipo de ereção, mas tanto a ereção reflexa como a psicogênica, muitas vezes, não são suficiente du radouras e consistentes para permitir a penetração vaginal. 
Em uma das pesquisas pioneiras que trata das alterações da função sexual em lesados medulares COMARR et al (1975), os autores consideram que o primeiro passo e o cuidadoso exame do paciente, alem de uma en trevista com ele e sua parceira sexual, para se analisar e discutir qual o grau de disfunção sexual que está alterado e, assim, iniciar um programa de orientações.

Já, BORELLl et al (1981) acreditam que cabe ao lesado medular escolher o melhor momento para expor seus problemas e, tambem, lembrar que a parceira pode estar curiosa, porém, com medo de abordar o assunto.

Acreditamos que tanto do prisma do paciente como da enfermeira, fazse necessária a coleta de dados, por meio da entrevista, num contexto geral, ou seja. inserido na avaliacão do paciente assim como se indaga sobre eliminações, cuidados com a pele, mobilidade, entre outros aspectos. No entanto, e de relevante importância conhecermos a vida sexual pregressa ou anterior a lesão medular. com a mesma importância quando se investiga sobre hábitos de sono, alimentação e hidratação, eliminação intestinal.

Outrossim, vale ressaltar que alguns pacientes, os mais jovens, anteriormente a lesão medular, ainda não haviam iniciado atividade sexual e estes merecem especial atenção com mais vagar, por não terem a vivência do que se considera um padrão de normalidade.

As mulheres portadoras de lesão medular necessitam de orientações não somente para o desenvolvimento da atividade sexual, mas alertá-la quanto às possibilidades de uma gestação. Atrelado a este fato então, é necessário, tambem, um programa para planejamento familiar.

Podemos perceber a importância de se abordar a temática em questão, não somente para a formulação do diagnóstico disfunção sexual. bem como para outros diagnósticos que certamente aparecerão e novas condutas terão que ser implementadas.

\section{CONCLUSÃO}

Diante dos resultados obtidos, podemos perceber que a coleta de dados acerca do paciente propicia o embasamento para uma assistência de enfermagem dinâmica, onde se visualizam seus resultados possibilitando uma melhora da qualidade de vida, o que necessita ser revista pelo enfermeiro, não só na esfera sexual, dos lesados medulares.

Assim, identificamos duas características definidoras referentes a inatividade sexual decorrente às alterações físicas e alterações nos processos eretil e ejaculatorio e, portanto. que as alteracões descritas pelos enfermeiros nos historicos de enfermagem fazem parte das características definidoras propostas pela NANDA, as quais foram verbalizadas pelos pacientes. 
FARO, A.C.M. e. The nursing diagnosis of sexual dysfunction: defining characteristics in spinal cord injuried patients. Rev.Eac.Enf.USP, v.29, n.2, p.166-72, aug. 1995.

The alterations of sexual function after spinal cord injury demands assistance because of cultural, psychological and biological aspects to keep. This study shows the defining characteristic, relacioned to nursing diagnosis sexual disfunction (NANDA), in spinal cord injuried patients on rehabilitation program.

UNITERMS: Sexual disfunction. Spinal cord injury. Rehabilitation.

\section{REFERÊNCIAS BIBLIOGRÁFICAS}

BOGOSSIAN, L. Traumatismo em geral: estudo etiopatológico dos traumas mecánicos. J. Bras. Med., v.41, p. 61.70, 1981.

BORELLI, M. et al. Lesão Medular: funçăo e orientaçăo sexual. Såo Paulo. Associação de Assistência à Criança Defeituosa, 1984. (Mimeografado).

COMARR, A.E. et al. Sexual function in traumatic paraplegia and quadriplegia. Am. J. Nurs., v. 75, p. $250-5,1975$.

CRIGLER, L. Sexual concerns of the spinal cord-injured. Nurs. Clin. North Am., v. 9. p. 703 16. 1974 .

FARIAS, J.N. et al. Diagnóstico de enfermagem: uma abordagem conceitual e prática. Joào Pessoa, Santa Marta. 1990.

FARO, A.C.M. e. Atuaçăo de enfermagem em um pronto socorro de ortopedia e traumatologia. Rev. Esc. Enf. USP. v. 21, n. 2. p. 161.70. 1987.

FARO, A.C.M. e. Estudo das alteraçōes da funçao sexual em homens paraplégicos. São Paulo. 1991. 98p. Dissertaçăo (Mestrado) - Escola de Enfermagem, Universidade de Såo Paulo.

MENDONÇA NETTO, A.B.F. de et al. Fraturas e luxaçoes da coluna dorso-lombar. Arq. Bras. Neuroc., v. 4, p. 97.102, 1985.

SANTOS. L.C.R. dos. Lesáo traumática da medula espinhal. Estudo retrospectivo de pacientes internados no Instituto de Ortopedia e Traumatologia do Hospital das Clínicas da Faculdade de Medicina da USP entre 1982 e 1987. Sao Paulo, 1989, 102p. Dissertação (Mestrado) - Escola de Enfermagem, Universidade de São Paulo.

SPICA, M.M. Sexual counselling standards for the spinal cord-injured. J. Neurosci. Nurs., v. 21, p. $56-60,1989$.

SPÓSITO. M.M. de M. et al. Paraplegia por lesão medular: estudo epidemiológico em pacientes atendidos para reabilitaçăo. Rev. Paul. Med.. v. 104, p. 196-202. 1986. 